\title{
LETRAMENTOS LITERÁRIOS NA CONTEMPORANEIDADE: CRITICIDADE E SUBVERSÃO
}

\author{
LITERARY LITERACY IN CONTEMPORARY TIMES: \\ CRITICALITY AND SUBVERSION
}

\author{
Cynthia Agra de Brito Neves* \\ Clecio dos Santos Bunzen Júnior ${ }^{\star *}$
}

\author{
somos todos latinos de mãos dadas ou não \\ pra sobreviver com as veias abertas \\ épreciso ter mais astúcia que o Chapolin Colorado ser mais Rebelde que a turma da série mexicana \\ pra praticar o internacionalismo proletariado \\ amar os cachorros como Trotsky amou a revolução lutar como Zapata: é o povo no poder \\ ou boicote à eleição \\ Émerson Alcalde
}

Letramentos literários são aqui compreendidos como práticas sociais que envolvem leituras, escutas, ilustrações, performances e/ou escritas literárias. Se antes o termo era comumente empregado, no singular, para se referir a teorias e práticas didático-pedagógicas de ensino de literatura na educação básica, atualmente, os letramentos literários, no plural, atravessam os muros escolares e o conceito se amplia para incorporar eventos e práticas literárias diversificados e onipresentes na sociedade contemporânea. A nosso ver, compreender os letramentos literários pela lente das práticas sociais de letramentos (Street, 2014) é essencial para (re)pensarmos os modos de produção, circulação e recepção da literatura como resistência e transgressão culturais nos processos complexos de formação de leitores e escritores literários, tal como requer uma educação literária e libertadora (Freire, 2019[1967]) em uma sociedade democrática.

Uma rápida pesquisa na internet logo revela a produção, circulação e recepção de gêneros literários diversos na atualidade: minicontos (microcontos ou nanocontos), crônicas, fanfictions (fanfics), instapoesias, poesias-slams, poesias-gifs, enfim, textos literários em prosa ou em versos, ora escritos, ora falados em voz alta, ora apresentados performaticamente (Zumthor, 2007), mas todos alvos de muitas curtidas em redes sociais. Podemos dizer que esses textos, também como processos de re-criação, têm sua função social, seu valor pragmático e artístico/literário determinados tanto pelos autores/narradores quanto pelos leitores/ouvintes. Trata-se, portanto, de novas formas de uma literatura que se abre à tensão entre corpo e tecnologia, às materialidades das vozes, dos sons, das presenças. Nesse cenário, os jovens são a grande maioria do público consumidor/leitor e produtor/autor desses (novos?) gêneros, pois é com eles e por meio deles que assumem a sua vez e a sua $v o z$ de criticidade e de subversão, o que explica, nesse sentido, o título deste dossiê.

Interessou-nos, portanto, reunir aqui artigos acadêmico-científicos que tratem de letramentos literários, articulando-os aos novos letramentos e aos multiletramentos, sob a perspectiva teórica de uma Linguística Aplicada indisciplinar (Moita Lopes, 2006) e crítica (Monte-Mór, 2019), que deseja uma educação libertadora (Freire, 2019[1967]), transgressora (bell hooks, 2017; Pennycook, 2006) e de(s)colonial (Walsh, 2009; Quijano, 2005; Lugones, 2014). De modo geral, acolhemos pesquisas no campo dos Estudos dos Letramentos em diálogo com a perspectiva da Educação Literária - especificamente, investigações que lançam reflexões críticas para as práticas de leitura e escrita literárias em diferentes espaços educativos, sejam eles formais, informais ou não-formais (Gohn, 2006).

Nessa direção, apresentamos neste dossiê letramentos literários que ocupam (ou melhor, invadem) projetos didáticos de ensino de literatura (canônica e não-canônica), seja em língua materna, seja em língua estrangeira, tanto na educação básica quanto na educação superior; letramentos literários presentes (ou não) nas avaliações oficiais de ensino (o Enem) e nos exames seletivos para ingresso em universidades (os vestibulares); letramentos literários

\footnotetext{
* Universidade Estadual de Campinas (Unicamp), Campinas, SP, Brasil. cynneves@unicamp.br. Orcid: https://orcid.org/0000-0002-5592-4409

** Universidade Federal de Pernambuco (UFPE), Recife, PE, Brasil. clecio.bunzen@ufpe.br.

Orcid: https://orcid.org/0000-0003-2311-963X
} 
em eventos de slams, saraus e coletivos, sempre voltados para a formação de jovens leitores e escritores de literatura numa perspectiva crítica e subversiva. Afinal, em tempos de pandemia e de pandemônio, letramentos literários de reexistência são precisos. Os processos de reexistência envolvem mediação em espaços e territórios diversos, fazendo com que a Linguística Aplicada possa, cada vez mais, se interessar pelo constante renascer no centro de diversas tensões políticas.

É precisamente com uma pesquisa participante e interventiva que nos brinda Claudiana Nogueira de Alencar, em seu texto "A escritura a escrevivência a invenção a poema': performances e decolonialidades nas gramáticas culturais das coletivas de poetas periféricas". Trata-se de um trabalho que une horizontalmente saberes populares e acadêmicos no Programa Viva a Palavra: uma série de projetos envolvendo coletivos e movimentos culturais da periferia em articulação com professores e estudantes da UECE. A participante-pesquisadora investiga a escrevivência literária de poetas mulheres de três coletivas da periferia de Fortaleza, e conclui que as práticas literárias, culturais e políticas dessas poetas constroem uma gramática cultural que, com suas palavras-sementes de poesias, aponta para uma sociedade matríztica, que se posiciona contra uma sociedade de dominação. O relato de Claudiana oferece-nos com essa feminização da resistência, uma proposta real, tecida com os corpos e as vozes autônomas, apoiadas no respeito mútuo e na construção coletiva; enfim, a feitura coletiva de uma sociedade em torno das políticas de dignidade e de esperança, nos fios do tear de Nina Rizzi:...podemos escrever tudo, o que desejamos mais profundamente. A poema é uma feitiçaria, uma arma, uma bomba!

Marcella dos Santos Abreu, Cláudia Hilsdorf Rocha e Ruberval Franco Maciel, em seu texto "Letramentos literários e translinguagem entre as ruas e as escolas do Sul Global: o Slam Interescolar como prática enativo-performativa decolonial", procuram visibilizar o Slam Interescolar de SP como letramentos literários juvenis, potencialmente críticos e transformativos, que desafiam as práticas monoglóssicas e as narrativas hegemônicas comuns às didáticas escolares, como faz a estudante do Ensino Médio, a poeta Franciele Evangelista Apolinário, na versão do Interescolar de SP 2020. Os autores analisam essa experiência estética da outridade, os aspectos poético-literários de um poema da aluna sob uma abordagem translíngue enativo-performativa, ratificando a potência das poesias-slams como gritos de resistência de jovens slammers e a importância da presença dos slams nas escolas paulistas.

No artigo "O poetry slam no ensino de língua espanhola: uma proposta para o letramento literário", Fabiana de Oliveira Souza recupera o histórico traçado por Neves (2021) sobre o Slam Interescolar de São Paulo para tomar o projeto educativo de Emerson Alcalde - o rapaz latino americano que epigrafa esta apresentação - com poesias em português como inspiração, e propor uma atividade pedagógica semelhante no ensino de língua espanhola suleado em escolas brasileiras. A proposta descrita passo a passo visa engajar os jovens estudantes na leitura, escuta, escrita e performance de poesias-slams em língua espanhola, promovendo assim uma educação intercultural, um letramento literário crítico, pautado nas perspectivas intercultural e decolonial de ensino de língua estrangeira.

Coletivoz Oficina de Saraus é um projeto educativo voltado para alunos da rede pública de ensino de Belo Horizonte. Esse projeto oferece oficinas de leitura literária, de escrita criativa e de performances poéticas à maneira dos saraus periféricos contemporâneos. Em "Práticas de letramentos literários de reexistência na Oficina de Sarau do Coletivoz Sarau de Periferia", Lucía Tennina, Marta Passos Pinheiro e Luiz Eduardo Rodrigues de Almeida Souza descrevem e analisam algumas das práticas de letramentos literários envolvendo oficineiros e estudantes que participam do projeto. Trabalhando com temáticas como identidade, criação artística e território, expõem a possibilidade de fazer de oficinas como essa uma "agência de letramento", de formação de cidadãos.

Bruno Cuter Albanese, em seu texto "Leituras transmídia de literatura por design: (sub)versões do cânone no Ensino Fundamental II", analisa o processo de leitura e adaptação da obra literária Senhora, de José de Alencar, para um curta-metragem por um grupo de alunos do nono ano do ensino fundamental de uma escola de rede particular do interior de São Paulo. As análises apontaram para uma apropriação surpreendentemente subjetiva do texto alencareano: os alunos ressignificaram elementos do romance subvertendo/transgredindo o cânone, aproximando-o a seus repertórios de mundo, especialmente a partir de referências de mídias audiovisuais, tomando assim a obra para a sua própria coleção.

É de uma investigação com base nas produções discentes de uma disciplina de língua inglesa no contexto do trabalho emergencial remoto que trata o artigo "(Sobre)Vivendo em meio ao caos: o potencial da literatura e do afeto na educação linguística crítica", de Guilherme Jotto Kawachi. O trabalho analisa um projeto em que práticas de letramentos literários são centrais para compreensão das discussões sociais, com destaque para as relações afetivas, 
para as vozes sociais do feminismo e para uma pedagogia da esperança em um contexto internacional marcado pelas estratégias de sobrevivência e de resistência.

Douglas Vinícius Souza Silva e Rodrigo Corrêa Martins Machado, em seu texto "Gêneros, sexualidades e práticas de letramentos literários: um olhar decolonial para as listas de leituras obrigatórias dos vestibulares", retomam os estudos sobre decolonialidade e colocam lentes analíticas nas leituras literárias obrigatórias para o ingresso de sete universidades públicas brasileiras. Os resultados indicam que o jogo de escolha se limita a determinadas diversidades, deixando de contemplar autores e obras LGBTQIA+. Neste sentido, os autores propõem reflexões importantes sobre o potencial estético, ético e político de contemplação de tais produções em um dos países mais violentos em relação às comunidades LGBTQIA+.

"Letramentos em disputa: o embate entre tradição e práticas literárias de reexistência no Exame Nacional do Ensino Médio" aprofunda a discussão sobre as práticas de leitura literária no processo de escolarização. Nesse artigo, Marcel Álvaro de Amorim e Tiago Cavalcante da Silva investigam quais letramentos literários são (des)legitimados nas questões que se constituem como discursos de reexistência, especificamente em três edições (2018-2020) do Exame Nacional do Ensino Médio (ENEM). Os resultados gerados mostram que, apesar da inclusão de textos literários de reexistência, há um jogo discursivo e tensões entre as práticas de letramento tradicionais e as chamadas pelos autores de "abertamente ideológicas".

Paula Aparecida Diniz Gomides, Gilcinei Teodoro Carvalho e Terezinha Cristina da Costa Rocha discutem, em "Literatura surda e percursos sócio-históricos de formação de leitores surdos", a formação de leitores nas comunidades surdas, enfocando as práticas sociais de letramento literário em que a Libras tem um papel central. $\mathrm{O}$ artigo apresenta uma discussão essencial para o campo da educação literária, pois traz relações entre a literatura surda e formação social e escolar dos surdos envolvidos na pesquisa. As experiências relatadas revelam o engajamento em práticas sociais de letramento literário, performances literárias nas redes sociais das/nas comunidades surdas, deslocando o olhar grafocêntrico para (re)pensarmos outros modos de produção de significados nas relações humanas.

\section{REFERÊNCIAS}

ALCALDE, E. Apenas mais um latino. In: Gênesis. São Paulo: Fala, 2020, p. 132. Performance disponível em: https://www. youtube. com/watch?v $=$ WrgVjuF3LT8.

FREIRE, P. Educação como prática da liberdade. São Paulo: Paz e Terra, 2019.

GOHN, M. da G. Educação não-formal, participação da sociedade civil e estruturas colegiadas nas escolas. Ensaio: aval. pol. públ. Educ., Rio de Janeiro, v.14, n.50, p. 27-38, jan./mar. 2006.

hooks, b. Ensinando a transgredir: a educação como prática da Liberdade. Trad. Marcelo B. Cipolla. 2a ${ }^{\text {a }}$ ed. São Paulo: Editora WMF Martins Fontes, 2017.

LUGONES, M. Rumo a um feminismo descolonial. Estudos Feministas, Florianópolis, 22(3): 320, setembro-dezembro/2014. (Artigo originalmente publicado na revista Hypatia, v. 25, n. 4, 2010. Traduzido com o consentimento da autora).

MOITA LOPES, L. P. da (Org.). Por uma linguística aplicada indisciplinar. São Paulo: Parábola, 2006.

MONTE MÓR, W. Letramentos críticos e expansão de perspectivas: diálogo sobre práticas. In: JORDÃO, C. M.; MARTINEZ, J. Z.; MONTE MÓR, W. (Orgs.). Letramentos em prática na formação inicial de professores de inglês. Campinas, SP: Pontes Editores, 2019.

NEVES, C. A. B. Letramentos literários em travessias na Linguística Aplicada: ensino transgressor e aprendizagem subjetiva da literatura. In: LIMA, E. (Org.) Linguística aplicada na Unicamp: travessias e perspectivas [livro eletrônico]. Bauru, SP: Canal 6, 2021, p. 65-88.

PENNYCOOK, A. Uma linguística aplicada transgressiva. In: MOITA LOPES, L. P. da (Org.). Por uma linguística aplicada indisciplinar. São Paulo: Parábola, 2006. 
QUIJANO, A. Colonialidade do poder, eurocentrismo e América Latina. In: LANDER, E. (Org.). A colonialidade do saber: eurocentrismo e ciências sociais. Perspectivas latino-americanas. Buenos Aires: Clacso, 2005, p. 227-278. (Colección Sur Sur).

STREET, B. Letramentos Sociais: abordagens críticas do letramento no desenvolvimento, na etnografia e na educação. Trad. Marcos Bagno. $1^{\text {a }}$. ed. São Paulo: Parábola Editorial, 2014.

WALSH, C. Interculturalidad, Estado, sociedad: luchas (de)coloniales de nuestra época. Quito: UASB/Abya-Yala, 2009.

ZUMTHOR, P. Performance, recepção, leitura. Trad. Jerusa Pires Ferreira e Suely Fenerich. São Paulo: Cosac Naify, 2007.

Recebido: 25/10/2021

Aceito: 25/10/2021

Publicado: 27/10/2021 